\title{
Current difficulties and recent advances in bypass therapy for the management of hemophilia with inhibitors: a new and practical formulation of recombinant factor Vlla
}

This article was published in the following Dove Press journal:

Drug Design, Development and Therapy

12 May 2011

Number of times this article has been viewed

\section{Linda Butros \\ Koh Boayue \\ Prasad Mathew}

The University of New Mexico, Albuquerque, New Mexico, USA
Correspondence: Prasad Mathew Director, Ted R. Montoya Hemophilia Program, Department of Pediatrics, MSC I0 5590, I University of New Mexico, Albuquerque, NM 87I3I, USA

$\mathrm{Tel}+\mathrm{I} 505272446$ I

Fax +I 5052728699

Email pmathew@salud.unm.edu

\begin{abstract}
Bypassing agents are the mainstay of treatment for patients with hemophilia with high-titer inhibitors. Whereas the availability of these agents has greatly advanced the management of bleeding episodes in this population, timely administration of bypassing agents continues to be hampered by a number of practical limitations, including the need for refrigerated storage of the agent and its reconstitution at room temperature prior to administration, among others. In this review, the importance of early treatment of bleeds and factors that influence this more timely therapeutic approach are highlighted, together with the advantages offered by the use of a new formulation of recombinant activated factor VII that permits improved storage and portability, potentially optimizing timely bypassing agent administration.
\end{abstract}

Keywords: hemophilia, inhibitors, bleeding, treatment, patients, recombinant factor VIIIa

\section{Introduction}

The development of neutralizing alloantibodies ("inhibitors") to factor VIII or factor IX complicates treatment in $20 \%$ to $30 \%$ of patients with hemophilia A and $3 \%$ to $5 \%$ of patients with hemophilia B. ${ }^{1}$ These inhibitors (polyclonal immunoglobulin $\mathrm{G}$ antibodies) also affect any residual endogenous factor that the patient may have and make administration of a replacement factor ineffective, secondary to its rapid clearance from the circulation. ${ }^{2,3}$ Treatment options, potential complications, and cost of treatment are markedly different for hemophilia patients with inhibitors than for hemophilia patients without inhibitors. ${ }^{1}$ Since patients with inhibitors no longer achieve adequate hemostasis with factor VIII or factor IX infusions, alternative treatments are required to reduce/eradicate inhibitor titers (eg, immune tolerance induction therapy) or induce coagulation via another pathway in the clotting cascade (ie, bypass therapy).

In this paper, we discuss the importance of early treatment of acute bleeds in patients with inhibitors, which offers a significant therapeutic advantage for minimizing re-bleeds, improves patient quality of life, and reduces consumption of bypassing agent. ${ }^{4}$ Early treatment can best be achieved by timely administration of bypassing therapy, which is dependent upon drug-related factors or properties that can either inhibit or facilitate this therapeutic goal in patients with inhibitors. Addressing this key point, we also detail the attributes of a new room temperature stable recombinant activated factor VII (rFVIIa) formulation that improves portability and convenience of administration, thereby increasing the likelihood of early and successful treatment of acute bleeding episodes in this patient population. 


\section{Importance of early treatment of acute bleeding episodes in inhibitor patients}

Available data suggest that early intervention improves treatment efficacy. ${ }^{4,5}$ Review of data from clinical trials and from studies of the compassionate use of rFVIIa have demonstrated a clear relationship between early treatment and achievement of excellent or effective treatment response, with $92 \%$ of patients achieving this endpoint when rFVIIa was initiated within a mean of 1.2 hours of the onset of bleeding versus only $63.1 \%$ when rFVIIa was given within a mean of 5 days after bleeding onset. ${ }^{5}$ Similarly, data from a prospective, observational registry comprising 128 bleeding episodes in 15 patients with inhibitors demonstrated numerically lower rebleeding rates among patients treated with rFVIIa within 2 hours (5.2\%) versus patients treated more than 2 hours after the first bleeding symptoms appeared (13.7\%). ${ }^{4}$ By minimizing the extent of bleeding in the joint, prompt treatment may also delay the development of hemophilic arthropathy. ${ }^{6}$ The improved efficacy of early treatment may also result in reduced bypassing agent consumption by patients. In the study by Lusher, the mean number of doses was lower among patients treated within a mean time interval of 1.2 hours (2.3 doses) than among patients treated within a mean time interval of 5 days ( 13.6 doses). ${ }^{5}$

Despite these findings showing the significant therapeutic benefit of early treatment of acute bleeds, timely management is not common among hemophilic youths in the United States. In a survey of 100 hemophilia patients aged 13 to 21 years, only $31 \%$ of respondents reported the administration of selftreatment within 1 hour of the onset of a bleeding episode. ${ }^{7}$ One of the most common reasons cited for treatment delay was the failure to have clotting factor with them at the time of the bleeding episode ( $25 \%$ of respondents). ${ }^{7}$

\section{Bypassing therapy for patients with inhibitors}

\section{Acute bleeding or perioperative bleeding management}

Historically, porcine factor VIII (pFVIII) has been used as an alternative to human-derived concentrates in patients with an inhibitor to factor VIII. ${ }^{8} \mathrm{pFVIII}$ has been observed to be $80 \%$ to $90 \%$ effective in patients with factor VIII inhibitors due to the low cross-reactivity to pFVIII. ${ }^{9-11}$ Plasma-derived pFVIII is no longer available because of a contamination with parvovirus ${ }^{12}$ but a recombinant $\mathrm{pFVIII}$ product is currently in clinical development. ${ }^{13}$ In patients with high-responding inhibitors (titer $>5 \mathrm{BU}$ ), acute bleeding is typically treated with an agent that bypasses the factor VIII or IX coagulation pathway, either activated prothrombin complex concentrates (aPCCs) or rFVIIa. ${ }^{2}$ In the United States, the only licensed aPCC is the plasma-derived factor VIII inhibitor bypassing activity, anti-inhibitor coagulant complex (FEIBA; Baxter AG, Vienna, Austria). Plasma-derived-aPCC (pd-aPCC) contains factor VII in mainly the activated form, as well as factor II, factor IX and factor X, in mainly non-activated forms. ${ }^{14}$ The precise mechanism by which pd-aPCC facilitates hemostasis is unknown, but prothrombin (factor II) and factor $\mathrm{Xa}$ are the primary active components, with other components including factor VIIa. ${ }^{14,15} \mathrm{~A}$ recent systematic review of available randomized clinical trial data showed that the pd-aPCC efficacy rate for controlling acute bleeding ranged from $64 \%$ to $80 \%$ of patients using dosing regimens according to published guidelines and manufacturer recommendations. ${ }^{16} \mathrm{Pd}-\mathrm{aPCC}$ is effective in controlling hemorrhage at a variety of anatomic sites including joint, muscle, mucocutaneous, and central nervous system (CNS) and perioperative bleeding, ${ }^{17-19}$ and can also be used effectively to achieve hemostasis in a home-treatment setting. ${ }^{14}$ Mild adverse events, such as chills, fever, nausea, and dizziness, occur in a small proportion of patients, ${ }^{20}$ and there is a small risk of anaphylactic reactions. ${ }^{21}$ Thrombotic and thromboembolic events (including disseminated intravascular coagulation [DIC], venous thrombosis, pulmonary embolism, myocardial infarction, and stroke) have been reported following infusion of pd-aPCC. ${ }^{21}$ Most of the thromboembolic events occurred when pd-aPCC was administered at doses higher than 200 units $/ \mathrm{kg} /$ day and in patients with other risk factors for thromboembolic events. ${ }^{14,21,22}$ Patients receiving more than 100 units $/ \mathrm{kg}$ of body weight of the concentrate must be monitored for the development of DIC and/or symptoms of acute coronary ischemia. ${ }^{21}$ In addition, the infusion time for this agent varies from about 30-45 minutes per infusion, to minimize side effects of rapid infusion. Since pd-aPCC is derived from human plasma, there is also the theoretical potential for human viral transmission, although no cases of hepatitis or human immunodeficiency virus infection have been directly linked to use of this agent. ${ }^{22,23}$ In addition, pd-aPCC contains trace amounts of factor VIII that may induce an anamnestic rise in factor VIII antibody titers in up to $30 \%$ of patients. ${ }^{19,21}$ This rise in antibody titers does not interfere with the efficacy of pd-aPCC and is transient in the majority of patients. ${ }^{20}$ Despite these limitations, this product has been widely used for about 30 years and continues to be used in patients who may not respond to rFVIIa. 
Recombinant factorVIIa is the other currently available bypassing agent that was approved by the US Food and Drug Administration (FDA) in 1999 for use in patients with inhibitors. In contrast to pd-aPCC, rFVIIa is a recombinant protein produced by genetically engineered mammalian cells (baby hamster kidney cell line) ${ }^{24}$ and has little to no risk of human viral transmission. ${ }^{25,26}$ Furthermore, because it does not contain any residual procoagulant factor VIII or factor IX activity, the risk of an anamnestic response is precluded, and this agent can be used for patients with inhibitors to factor VIII or factor IX. ${ }^{23}$ In clinical studies, rFVIIa has been shown to be effective in restoring hemostasis in hemophilia $\mathrm{A}$ and hemophilia B patients with inhibitors who were experiencing joint, muscle, dental, and CNS bleeds, or who underwent major and minor surgeries. ${ }^{27-32} \mathrm{An}$ estimate of rFVIIa efficacy for controlling bleeding derived from a recent systematic analysis of available randomized clinical trial data showed an effective treatment response rate of $81 \%$ to $91 \%$ in patients with inhibitors experiencing acute bleeds. ${ }^{16}$ The most commonly reported adverse events in clinical studies were mild and included fever, skin reactions, headache, hypertension, epistaxis, shortened prothrombin time, and reduced fibrinogen levels. ${ }^{20}$ The risk of thromboembolic events with rFVIIa is low and similar to that observed with pd-aPCC. ${ }^{2}$

Although both types of bypassing agents can be administered at home, rFVIIa may be more suited to this use because it is a low-volume injection that can be administered rapidly. However, rFVIIa has to be administered frequently, every 2 to 3 hours because of its shorter half-life, whereas the recommended interval between doses of pd-aPCC is 6 to 12 hours. ${ }^{21}$ The FEIBA NovoSeven Comparative (FENOC) Study was a head-to-head comparison of efficacy between pd-aPCC and rFVIIa, and was conducted as a prospective, open-label, crossover, randomized equivalency-designed clinical trial in which a difference in response at 6 hours after treatment of no more than $15 \%$ was determined to be clinically equivalent. ${ }^{33} \mathrm{At}$ 6 hours in the FENOC Study, the confidence interval reported for each product only slightly exceeded the $15 \%$ boundary $(-11.4 \%$ to $15.7 \%, P=0.059)$. The investigators, however, noted that their study was not designed nor adequately powered to provide evidence of the superiority of either product. They further suggested that an individualized approach to therapy should be used to optimize therapy, as there was evidence of substantial interpatient variability. ${ }^{33}$

\section{Prophylaxis}

Because of the clear benefit of preventing hemarthrosis for the preservation of joint integrity and maintenance of mobility and function, ${ }^{34}$ prophylaxis with factor VIII or IX is used routinely in many developed countries. Similarly, prophylaxis with bypassing agents is also being considered in inhibitor patients to minimize or prevent bleeding episodes. The prophylactic use of bypassing agents has been examined in a randomized clinical trial and several small series of patients with hemophilia A and inhibitors. In a recent trial, 22 patients with inhibitors to factor VIII were randomized to once-daily injections of rFVIIa $90 \mathrm{mcg} / \mathrm{kg}$ or $270 \mathrm{mcg} / \mathrm{kg}$ prophylaxis for 3 months ${ }^{35} \mathrm{rFVII}$ treatment reduced the number of bleeds ( $45 \%-59 \% ; P<0.0001$ versus no prophylaxis) and reduced hospital admissions and work/ school absences. Effects on bleeding frequency were largely maintained throughout a 3-month post-prophylaxis evaluation period. In many reports from case series, pd-aPCC and rFVIIa appeared to be effective and well tolerated as prophylactic therapy, with a reduced incidence of bleeding episodes, fewer workdays missed, improved quality of life, and less need for on-demand therapy, all variously reported. ${ }^{36-42}$ However, concerns have been raised about the risks (particularly of thromboembolism) with repeated and frequent use of pd-aPCC and the potential for anamnestic increases in antibody titers. ${ }^{43}$ Although the available data on prophylaxis are promising, much more research is required before the prophylactic use of bypassing agents becomes routine practice, in particular, in terms of defining the optimal regimen to use in this setting, the long-term risks and benefits, and the cost-utility of this approach.

\section{Limitations}

The availability of bypass agents has greatly advanced the treatment of hemophilia in patients with inhibitors; however, a few product-related practical limitations remain. Neither pd-aPCC nor the original formulation of rFVIIa are sufficiently stable at room temperature to be stored or transported without refrigeration..$^{21,44}$ Thus, availability of product when away from home is dependent on an individual's willingness to carry a cooler. Delays in treatment also arise from the need to restore these agents to room temperature prior to reconstitution. ${ }^{21,44}$

\section{New advance in formulation: room temperature stable rFVIIa}

A room temperature stable formulation of rFVIIa (rFVIIa-RT; NovoSeven ${ }^{\circledR}$ RT; Novo Nordisk A/S, Bagsvaerd, Denmark) ${ }^{44}$ was approved by the FDA in May 2008. Studies have shown that this product can be stored at temperatures of $2^{\circ} \mathrm{C}$ to $25^{\circ} \mathrm{C}\left(36^{\circ} \mathrm{F}-77^{\circ} \mathrm{F}\right)$ for up to 2 years 
prior to reconstitution and for up to 3 hours following reconstitution..$^{45}$ In addition, the concentration of this formulation was changed to make dosing calculations easier, and the vials are color coded to decrease confusion between the different vial sizes.

\section{Stability}

The stability of rFVIIa-RT, both in lyophilized and reconstituted forms, has been tested in a range of potential storage conditions. ${ }^{45}$ As reported in the study by Nedergaard et al, the specific activity of FVIIa in a $5 \mathrm{mg}$ dose of rFVIIa-RT

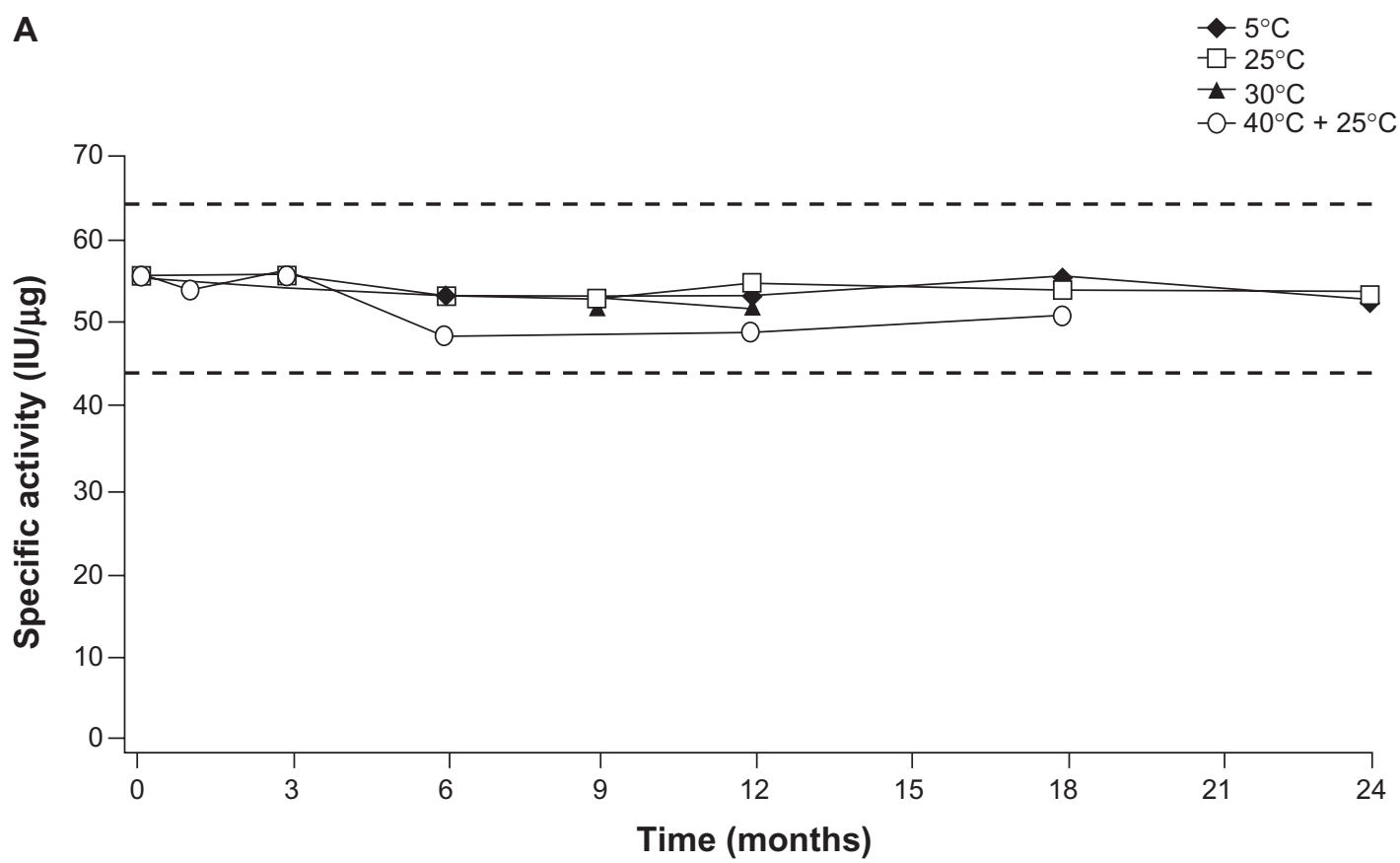

B

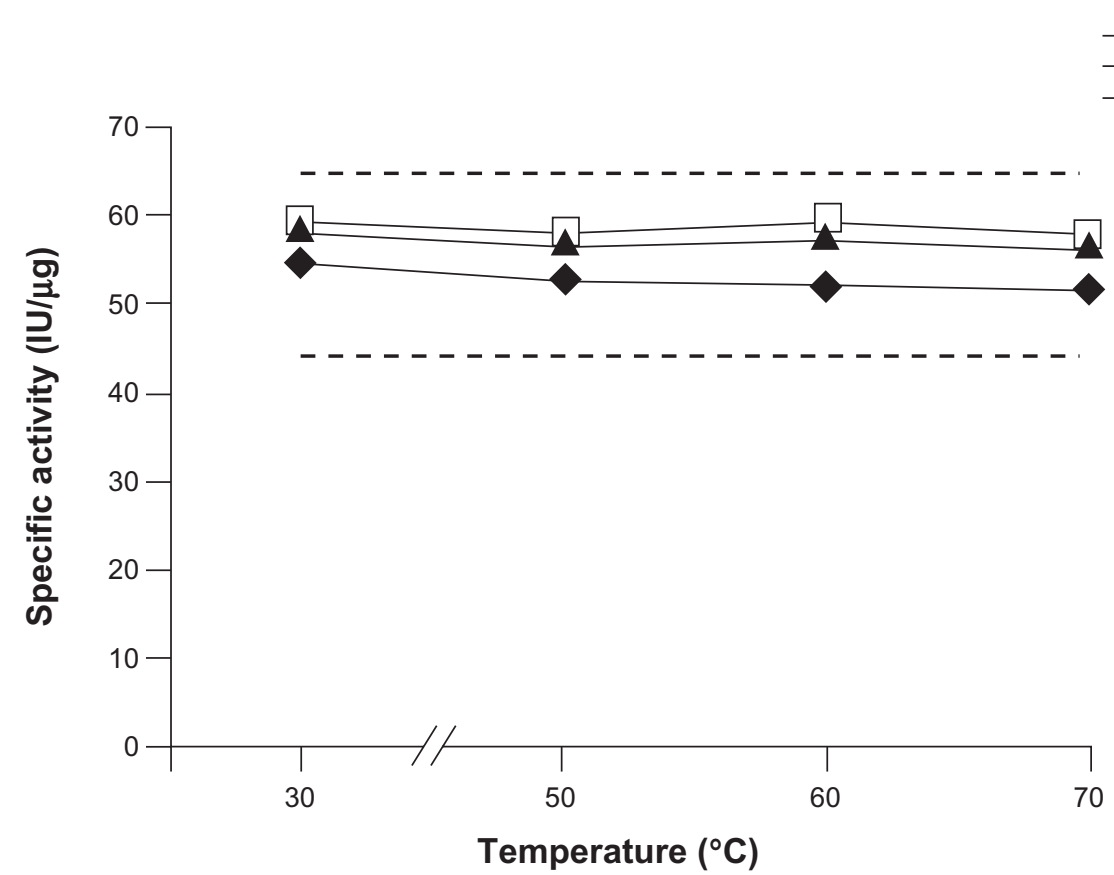

Figure I A) Specific activity of the room temperature stable formulation of activated recombinant factor VII ( $\mathrm{rFVIla}-\mathrm{RT}$ ) during long-term storage at $5^{\circ} \mathrm{C} / 4 \mathrm{I}^{\circ} \mathrm{F}, 25^{\circ} \mathrm{C} / 77^{\circ} \mathrm{F}$, and $30^{\circ} \mathrm{C} / 86^{\circ} \mathrm{F}$, and during long-term storage at $40^{\circ} \mathrm{C} / 104^{\circ} \mathrm{F}$ for 6 months followed by an additional $12 \mathrm{months}$ at $25^{\circ} \mathrm{C} / 77^{\circ} \mathrm{F}$. Data for the $1 \mathrm{mg}$, $2 \mathrm{mg}$, and $5 \mathrm{mg}$ product sizes were equivalent. Results from the $5 \mathrm{mg}$ size are presented. B) Specific activity of rFVIla-RT during storage at extreme temperatures for 12 hours. The broken lines represent the allowable upper and lower limit for each test parameter at the end of the product's shelf-life, as adopted by the European Medicines Agency and the US Food and Drug Administration. ${ }^{45}$

This article was published in Clinical Therapeutics, Nedergaard et al. ${ }^{45}$ Copyright (C) 2008, Elsevier. 
lyophilized product was maintained after 24 months of storage at $5^{\circ} \mathrm{C}\left(41^{\circ} \mathrm{F}\right)$ and $25^{\circ} \mathrm{C}\left(77^{\circ} \mathrm{F}\right)$, after 12 months and 18 months of storage at $30^{\circ} \mathrm{C}\left(86^{\circ} \mathrm{F}\right)$, and after 6 months at $40^{\circ} \mathrm{C}\left(104^{\circ} \mathrm{F}\right)$ followed by an additional 12 months at $25^{\circ} \mathrm{C}$ $\left(77^{\circ} \mathrm{F}\right.$ ) (Figure 1A). ${ }^{45}$ Moreover, rFVIIa-RT continued to maintain activity and was generally stable after 12 hours of storage at extreme temperatures $\left(50^{\circ} \mathrm{C}\left[122^{\circ} \mathrm{F}\right], 60^{\circ} \mathrm{C}\right.$ $\left[140^{\circ} \mathrm{F}\right]$, and $70^{\circ} \mathrm{C}\left[158^{\circ} \mathrm{F}\right]$ ) (Figure $\left.1 \mathrm{~B}\right),{ }^{45}$ such as those that might be encountered during routine transport by patients. Stability and specific activity were also maintained when the rFVIIa-RT formulation was stored in the refrigerator $\left(5^{\circ} \mathrm{C}\right.$ $\left.\left[41^{\circ} \mathrm{F}\right]\right)$ and then at high room temperature $\left(30^{\circ} \mathrm{C}\left[86^{\circ} \mathrm{F}\right]\right)$ for alternating periods over 5 days. Stability was independent of vial size. ${ }^{45}$

After reconstitution with histidine diluents, the rFVIIa-RT formulation retained its activity and stability when stored for 6 hours at $25^{\circ} \mathrm{C}\left(77^{\circ} \mathrm{F}\right)$ and for 24 hours at $5^{\circ} \mathrm{C}\left(41^{\circ} \mathrm{F}\right) .^{45}$ Another study demonstrated that rFVIIa-RT remained physically and chemically stable at $25^{\circ} \mathrm{C}\left(77^{\circ} \mathrm{F}\right)$ for 6 hours after reconstitution with sterile water for injection, physiologic saline, or histidine diluent (Table 1). ${ }^{46}$ In this study, rFVIIa-RT was also shown to be stable at $5^{\circ} \mathrm{C}\left(41^{\circ} \mathrm{F}\right)$ for up to 24 hours when reconstituted with inappropriate diluents (sterile water for injection or physiologic saline) or the recommended histidine diluent. This is of interest to note in urgent or critical situations where only sterile saline or water for injection may be available for reconstitution. rFVIIa-RT stability is also maintained with various "incorrect" volumes of diluent. ${ }^{46}$ Reconstitution in double or half of the histidine solvent does not adversely affect stability; however, there is still a potential for dosing errors because the target final dose cannot be achieved if the correct diluent volume is not used. ${ }^{46}$
Stability at room temperature for this product was achieved through the addition of 2 new excipients to the lyophilized powder - a stabilizer (sucrose) and an antioxidant (methionine) - and by the use of a diluent containing histidine $10 \mathrm{mmol} / \mathrm{L}$ in sterile water. Histidine, a naturally occurring amino acid, is used as a buffering agent in other marketed factor replacement products and thus has a history of safe use in this patient population. ${ }^{45,46}$

\section{Vial sizes}

To aid in dose calculations at home, the concentration of rFVIIa-RT was changed to $1 \mathrm{mg} / \mathrm{mL}$, and rFVIIa-RT is available in single-use vials containing $1 \mathrm{mg}, 2 \mathrm{mg}$, or $5 \mathrm{mg}$ of rFVIIa-RT per vial. This is in contrast to the original rFVIIa preparation, which was available in $1.2 \mathrm{mg}, 2.4 \mathrm{mg}$, and $4.8 \mathrm{mg}$ vial sizes. Because it is $40 \%$ more concentrated than the original $\mathrm{rFVIIa}$ formulation, the RT formulation allows for a lower infusion volume, and thus faster infusion than the original product. ${ }^{47}$ To make administration easier and avoid confusion, the vials of rFVIIa-RT and corresponding vials of premeasured diluent now have matching color-coded caps to aid in differentiating between vials and to avoid medication errors.

\section{Pharmacokinetic and pharmacodynamic equivalence}

Pharmacokinetic and pharmacodynamic equivalence of rFVIIa-RT with original rFVIIa was demonstrated in a randomized, double-blind, 2-way crossover study in healthy volunteers. ${ }^{48}$ Factor VII activity over time was nearly identical with the 2 formulations (Figure $2 \mathrm{~A}),{ }^{48}$ and the $90 \%$ confidence intervals for difference in the primary end point of area under the curve was 0.93 , well within the 0.8 to 1.25 definition of bioequivalence. Coagulation

Table I In vitro stability of rFVlla-RT after reconstitution with correct volumes of inappropriate solvents (sterile water for injection or saline) and the appropriate histidine solvent ${ }^{46}$

\begin{tabular}{|c|c|c|c|c|c|c|c|}
\hline $\begin{array}{l}\text { Storage } \\
\text { time (h) }\end{array}$ & $\begin{array}{l}\text { Storage } \\
\text { temperature }\left({ }^{\circ} \mathrm{C} /{ }^{\circ} \mathrm{F}\right)\end{array}$ & $\begin{array}{l}\text { Concentration } \\
(\mathrm{mg} / \mathrm{mL})\end{array}$ & $\begin{array}{l}\text { Dimer/oligomer } \\
\text { formation (\%) }\end{array}$ & $\begin{array}{l}\text { Polymer } \\
\text { formation }^{\text {a }}(\%)\end{array}$ & $\begin{array}{l}\text { Heavy chain } \\
\text { degradation (\%) }\end{array}$ & $\begin{array}{l}\text { Oxidized } \\
\text { forms (\%) }\end{array}$ & pH \\
\hline \multicolumn{8}{|c|}{ rFVIIa-RT I mg reconstituted with I.I5 mL recommended solvent (histidine) } \\
\hline 0 & - & 0.97 & 1.4 & $<0.3$ & 8.5 & 1.2 & 6.1 \\
\hline 6 & $25 / 77$ & 0.99 & 1.3 & $<0.3$ & 8.6 & 1.2 & 6.1 \\
\hline \multicolumn{8}{|c|}{ rFVIla-RT I mg reconstituted with $\mathrm{I} .15 \mathrm{~mL}$ sterile water } \\
\hline 0 & $25 / 77$ & 0.96 & 1.5 & $<0.3$ & 8.8 & 1.2 & 6.0 \\
\hline 6 & $25 / 77$ & 0.95 & 1.3 & $<0.3$ & 8.7 & 1.2 & 6.0 \\
\hline \multicolumn{8}{|c|}{ rFVIla-RT I mg reconstituted with I.I5 mL physiologic saline } \\
\hline 0 & $25 / 77$ & 0.97 & 1.5 & $<0.3$ & 8.7 & 1.2 & 6.0 \\
\hline 6 & $25 / 77$ & 0.98 & 1.5 & $<0.3$ & 8.6 & 1.2 & 6.0 \\
\hline
\end{tabular}

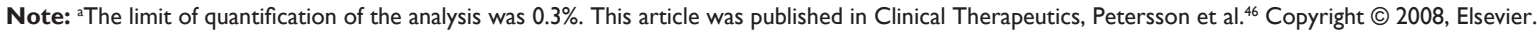

Abbreviation: rFVIla-RT, room temperature stable activated recombinant factor VII. 


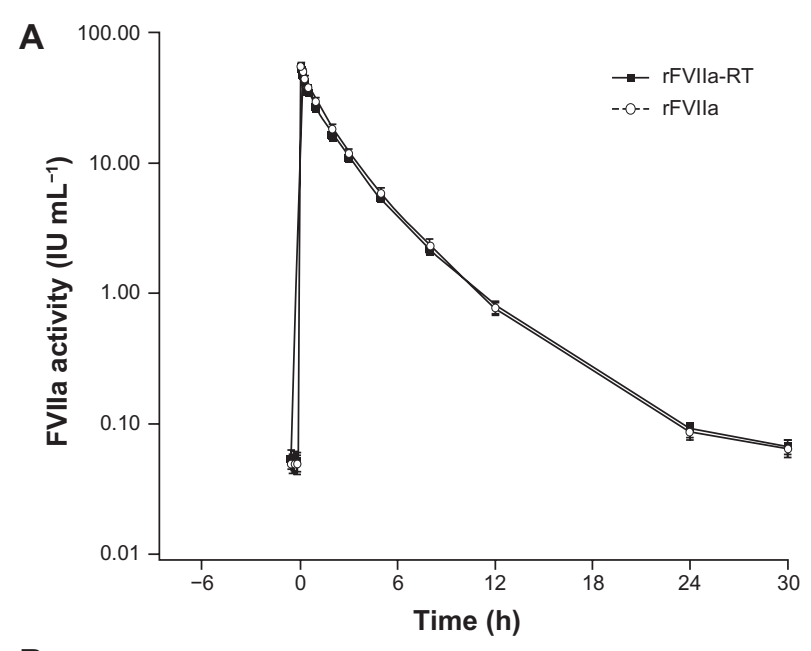

B

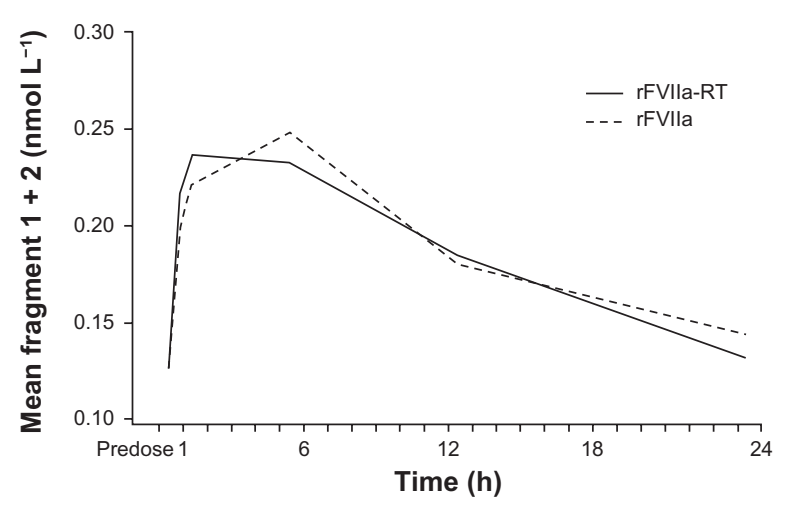

C

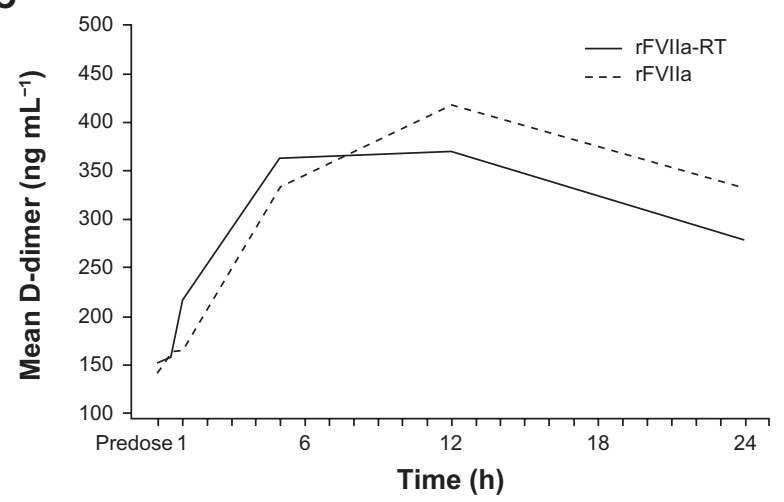

Figure 2 Comparison of the time course of effect of original activated recombinant

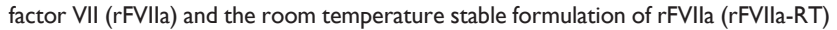
in a single-dose, randomized, crossover study. ${ }^{48}$ A) Mean (SD) plasma-activated rFVIla activity (logarithmic scale); B) Mean prothrombin fragment $\mathrm{F}_{1+2}$ levels; C) Mean D-dimer levels.

Copyright (C) 2007, John Wiley \& Sons. Reproduced with permission from Bysted et al. ${ }^{48}$

parameters, including levels of prothrombin fragment $\mathrm{F}_{1+2}$ (Figure $\left.2 \mathrm{~B}\right)^{48}$ and $\mathrm{D}$ dimer (Figure $2 \mathrm{C}$ ), ${ }^{48}$ activated partial thromboplastin time at 30 minutes postdose, and prothrombin time at 5 hours and 24 hours postdose, were also similar with the 2 formulations. Mean pharmacokinetic profiles were similar for the 2 formulations and are
Table 2 Pharmacokinetic parameters after administration of single $90 \mu \mathrm{g} / \mathrm{kg}$ doses of original rFVIla or rFVIla-RT in a randomized crossover study ${ }^{48}$

\begin{tabular}{|c|c|c|}
\hline \multirow{2}{*}{$\begin{array}{l}\text { Mean (SD) pharmacokinetic } \\
\text { parameter }\end{array}$} & \multicolumn{2}{|l|}{ rFVIIa } \\
\hline & $\begin{array}{l}\text { Original } \\
(n=22)\end{array}$ & $\begin{array}{l}\text { RT } \\
(n=22)\end{array}$ \\
\hline $\mathrm{AUC}_{0-\mathrm{t}}, \mathrm{h} / \mathrm{IU} / \mathrm{mL}$ & $122.04(18.03)$ & $113.26(17.36)^{a}$ \\
\hline$C_{\max }, I U / m L$ & $55.44(7.89)$ & $52.83(7.31)$ \\
\hline $\mathrm{AUC}_{0-30}, \mathrm{~h} / \mathrm{IU} / \mathrm{mL}$ & $122.05(18.01)$ & II 3.26 (I7.36) \\
\hline$t_{1 / 2}, h$ & $3.48(0.27)$ & $3.54(0.28)$ \\
\hline Mean residence time, $\mathrm{h}$ & $2.97(0.26)$ & $3.05(0.27)$ \\
\hline $\mathrm{CL}, \mathrm{mL} / \mathrm{h} / \mathrm{kg}$ & $37.63(5.99)$ & $40.43(6.23)$ \\
\hline $\mathrm{V}_{c}, \mathrm{~mL} / \mathrm{kg}$ & $82.68(12.50)$ & $86.36(12.31)$ \\
\hline $\mathrm{V}_{\mathrm{ss}}, \mathrm{mL} / \mathrm{kg}$ & III.3। (I7.52) & $122.96(20.42)$ \\
\hline
\end{tabular}

Notes: ${ }^{\mathrm{P}} \mathrm{P}=0.1076$ for RT vs original formulation.

Copyright $\odot$ 2007, John Wiley and Sons. Reproduced with permission from Bysted et al..$^{48}$

Abbreviations: rFVlla, activated recombinant factor Vll; rFVlla-RT, room temperature stable rFVlla; $\mathrm{SD}$, standard deviation; AUC, area under the curve; $\mathrm{C}_{\text {max }}$ ' maximal concentration; $t_{1 / 2}$, half-life; $C L$, clearance; $V_{c}$, volume of distribution in the central compartment; $\mathrm{V}_{\mathrm{ss}}$, volume of distribution at steady state.

summarized in Table $2 .{ }^{48} \mathrm{~A}$ comparable hemostasis profile was demonstrated by consistent measures of coagulation and fibrinolysis. No adverse events were reported with the RT formulation in this study. In addition, no subjects developed treatment-related factor VIIa antibodies during the course of the trial. ${ }^{48}$

\section{Conclusion}

Despite remarkable advances in the treatment of hemophilia in recent decades, unmet clinical needs still exist, particularly for patients whose condition is complicated by the development of high-titer inhibitors. Although long-term eradication of inhibitors by immune tolerance is desirable, the mainstay of treatment is the use of bypassing agents to treat acute bleeding episodes. The development of the rFVIIa-RT formulation allows immediate access through an improvement in portability, ease of storage, and the time needed for reconstitution, and should be a benefit to patients with hemophilia and inhibitors and their providers.

\section{Disclosure}

Editorial support was provided by ETHOS Health Communications, through financial support from Novo Nordisk Inc, in compliance with international Good Publication Practice guidelines. Dr Mathew has received research and educational funding at The University of New Mexico from the following companies: Bayer HealthCare Pharmaceuticals, Baxter Healthcare Corporation, CSL Behring, Novo Nordisk Inc, and Wyeth Pharmaceuticals. Drs Butros and Boayue have nothing to disclose. 


\section{References}

1. Berntorp E, Shapiro A, Astermark J, et al. Inhibitor treatment in haemophilias A and B: summary statement for the 2006 international consensus conference. Haemophilia. 2006;12 Suppl 6:S1-S7.

2. Acharya SS, DiMichele DM. Management of factor VIII inhibitors. Best Pract Res Clin Haematol. 2006;19(1):51-66.

3. Dimichele DM. Management of factor VIII inhibitors. Int J Hematol. 2006;83(2):119-125.

4. Salaj P, Brabec P, Penka M, et al. Effect of rFVIIa dose and time to treatment on patients with haemophilia and inhibitors: analysis of HemoRec registry data from the Czech Republic. Haemophilia. 2009; 15(3):752-759.

5. Lusher JM. Early treatment with recombinant factor VIIa results in greater efficacy with less product. Eur J Haematol Suppl. 1998; 63:7-10.

6. Raffini L, Manno C. Modern management of haemophilic arthropathy. Br J Haematol. 2007;136(6):777-787.

7. Nazzaro AM, Owens S, Hoots WK, Larson KL. Knowledge, attitudes, and behaviors of youths in the US hemophilia population: results of a national survey. Am J Public Health. 2006;96(9):1618-1622.

8. Lee CA. The evidence behind inhibitor treatment with porcine factor VIII. Pathophysiol Haemost Thromb. 2002;32 Suppl 1:5-8.

9. Hay CR. Porcine factor VIII: current status and future developments. Haemophilia. 2002;8 Suppl 1:24-27; discussion 28-32.

10. Brettler DB, Forsberg AD, Levine PH, et al. The use of porcine factor VIII concentrate (Hyate:C) in the treatment of patients with inhibitor antibodies to factor VIII. A multicenter US experience. Arch Intern Med. 1989;149(6):1381-1385.

11. Hay CR, Lozier JN, Lee CA, et al. Safety profile of porcine factor VIII and its use as hospital and home-therapy for patients with haemophilia-A and inhibitors: the results of an international survey. Thromb Haemost. 1996;75(1):25-29

12. Orkin SH, Nathan DG, Ginsburg D, Look AT, editors. Nathan and Oski's Hematology of Infancy and Childhood. 7th ed. Philadelphia: Saunders, Elsevier; 2009.

13. Toschi V. OBI-1, porcine recombinant Factor VIII for the potential treatment of patients with congenital hemophilia A and alloantibodies against human Factor VIII. Curr Opin Mol Ther. 2010;12(5):617-625.

14. Luu H, Ewenstein B. FEIBA safety profile in multiple modes of clinical and home-therapy application. Haemophilia. 2004;10 Suppl 2:10-16.

15. Negrier C, Gomperts ED, Oldenburg J. The history of FEIBA: a lifetime of success in the treatment of haemophilia complicated by an inhibitor. Haemophilia. 2006;12 Suppl 5:4-13.

16. Knight C, Dano AM, Kennedy-Martin T. Systematic review of efficacy of rFVIIa and aPCC treatment for hemophilia patients with inhibitors. Adv Ther. 2009;26(1):68-88.

17. Hilgartner M, Aledort L, Andes A, Gill J. Efficacy and safety of vaporheated anti-inhibitor coagulant complex in hemophilia patients. FEIBA Study Group. Transfusion. 1990;30(7):626-630.

18. Hilgartner MW, Knatterud GL. The use of factor eight inhibitor by-passing activity (FEIBA immuno) product for treatment of bleeding episodes in hemophiliacs with inhibitors. Blood. 1983;61(1): 36-40.

19. Negrier C, Goudemand J, Sultan Y, Bertrand M, Rothschild C, Lauroua P. Multicenter retrospective study on the utilization of FEIBA in France in patients with factor VIII and factor IX inhibitors. French FEIBA Study Group. Factor Eight Bypassing Activity. Thromb Haemost. 1997;77(6):1113-1119.

20. Lloyd Jones M, Wight J, Paisley S, Knight C. Control of bleeding in patients with haemophilia A with inhibitors: a systematic review. Haemophilia. 2003;9(4):464-520.

21. FEIBA NF (Anti-Inhibitor Coagulant Complex), Nanofiltered and Vapor Heated [package insert]. Vienna. Austria: Baxter AG; 2010.

22. Gomperts ED. FEIBA safety and tolerability profile. Haemophilia. 2006;12 Suppl 5:14-19.

23. Mathew P. Current opinion on inhibitor treatment options. Semin Hematol. 2006;43(2 Suppl 4):S8-S13.
24. Persson E, Bolt G, Steenstrup TD, Ezban M. Recombinant coagulation factor VIIa - from molecular to clinical aspects of a versatile haemostatic agent. Thromb Res. 2010;125(6):483-489.

25. Lapecorella M, Mariani G. Factor VII deficiency: defining the clinical picture and optimizing therapeutic options. Haemophilia. 2008; 14(6):1170-1175.

26. Hedner U. Recombinant factor VIIa: its background, development and clinical use. Curr Opin Hematol. 2007;14(3):225-229.

27. Bech RM. Recombinant factor VIIa in joint and muscle bleeding episodes. Haemostasis. 1996;26 Supp1 1:135-138.

28. Ingerslev J, Freidman D, Gastineau D, et al. Major surgery in haemophilic patients with inhibitors using recombinant factor VIIa. Haemostasis. 1996;26 Suppl 1:118-123.

29. Key NS, Aledort LM, Beardsley D, et al. Home treatment of mild to moderate bleeding episodes using recombinant factor VIIa (NovoSeven) in haemophiliacs with inhibitors. Thromb Haemost. 1998;80(6): 912-918.

30. Lusher JM, Roberts HR, Davignon G, et al. A randomized, double-blind comparison of two dosage levels of recombinant factor VIIa in the treatment of joint, muscle and mucocutaneous haemorrhages in persons with haemophilia A and B, with and without inhibitors. rFVIIa Study Group. Haemophilia. 1998;4(6):790-798.

31. Shapiro AD, Gilchrist GS, Hoots WK, Cooper HA, Gastineau DA. Prospective, randomised trial of two doses of rFVIIa (NovoSeven) in haemophilia patients with inhibitors undergoing surgery. Thromb Haemost. 1998;80(5):773-778.

32. Lusher JM. Acute hemarthroses: the benefits of early versus late treatment with recombinant activated factor VII. Blood Coagul Fibrinolysis. 2000;11 Suppl 1:S45-S49.

33. Astermark J, Donfield SM, DiMichele DM, et al. A randomized comparison of bypassing agents in hemophilia complicated by an inhibitor: the FEIBA NovoSeven Comparative (FENOC) Study. Blood. 2007;109(2):546-551.

34. Manco-Johnson MJ, Abshire TC, Shapiro AD, et al. Prophylaxis versus episodic treatment to prevent joint disease in boys with severe hemophilia. N Engl J Med. 2007;357(6):535-544.

35. Konkle BA, Ebbesen LS, Erhardtsen E, et al. Randomized, prospective clinical trial of recombinant factor VIIa for secondary prophylaxis in hemophilia patients with inhibitors. J Thromb Haemost. 2007;5(9): 1904-1913.

36. Hilgartner MW, Makipernaa A, Dimichele DM. Long-term FEIBA prophylaxis does not prevent progression of existing joint disease. Haemophilia. 2003;9(3):261-268.

37. Tcheng WY, Donkin J, Konzal S, Wong WY. Recombinant factor VIIa prophylaxis in a patient with severe congenital factor VII deficiency. Haemophilia. 2004;10(3):295-298.

38. Siegmund B, Richter H, Pollmann H. Prophylactic treatment with FEIBA of a haemophilia A patient with inhibitor: what are the costs, what are the benefits? Haemophilia. 2005;11(6):638-641.

39. Young G, McDaniel M, Nugent DJ. Prophylactic recombinant factor VIIa in haemophilia patients with inhibitors. Haemophilia. 2005; 11(3):203-207.

40. Leissinger CA, Becton DL, Ewing NP, Valentino LA. Prophylactic treatment with activated prothrombin complex concentrate (FEIBA) reduces the frequency of bleeding episodes in paediatric patients with haemophilia A and inhibitors. Haemophilia. 2007;13(3): 249-255.

41. Morfini M, Auerswald G, Kobelt RA, et al. Prophylactic treatment of haemophilia patients with inhibitors: clinical experience with recombinant factor VIIa in European Haemophilia Centres. Haemophilia. 2007;13(5):502-507.

42. Ohga S, Nomura A, Takada H, Suga N, Hara T. Successful self-infusion of activated prothrombin complex concentrate for prophylaxis in a child with a factor VIII inhibitor. Am J Hematol. 2007;82(2):145-149.

43. Leissinger CA. Prevention of bleeds in hemophilia patients with inhibitors: emerging data and clinical direction. Am J Hematol. 2004; 77(2):187-193. 
44. NovoSeven ${ }^{\circledR}$ RT [Coagulation Factor VIIa (Recombinant)] Room Temperature Stable [prescribing information]. Novo Nordisk, Princeton, NJ; August 2010.

45. Nedergaard H, Vestergaard S, Jensen PT, et al. In vitro stability of lyophilized and reconstituted recombinant activated factor VII formulated for storage at room temperature. Clin Ther. 2008;30(7):1309-1315.

46. Petersson B, Schonwandt AB, Thornstfeldt $\mathrm{P}$, et al. In vitro stability of two formulations of recombinant activated factor VIIa reconstituted in inappropriate solvents or at inappropriate volumes. Clin Ther. 2008; 30(5):917-923.
47. Mathew P, Cooper D, Bjerre J. Room temperature stable recombinant activated factor VIII: implications for patients, physicians, hospitals and formulary decision makers. Manag Care Interface. 2008;21: $8-13$.

48. Bysted BV, Scharling B, Moller T, Hansen BL. A randomized, doubleblind trial demonstrating bioequivalence of the current recombinant activated factor VII formulation and a new robust $25^{\circ} \mathrm{C}$ stable formulation. Haemophilia. 2007;13(5):527-532.

\section{Publish your work in this journal}

Drug Design, Development and Therapy is an international, peerreviewed open-access journal that spans the spectrum of drug design and development through to clinical applications. Clinical outcomes, patient safety, and programs for the development and effective, safe, and sustained use of medicines are a feature of the journal, which has also been accepted for indexing on PubMed Central. The manuscript management system is completely online and includes a very quick and fair peer-review system, which is all easy to use. Visit http://www.dovepress.com/testimonials.php to read real quotes from published authors.

Submit your manuscript here: http://www.dovepress.com/drug-design-development-and-therapy-journal 